\title{
Effect of heavy metal contamination on the plasticity of kaolin- bentonite clay mixtures and an illite-smectite rich natural clay
}

\author{
Abdulla Muththalib ${ }^{1, *}$, and Béatrice A. Baudet ${ }^{1}$ \\ ${ }^{1}$ University College London, WC1E 6BT, United Kingdom
}

\begin{abstract}
The behaviour of soil is complex in a natural environment. Contamination of soil with organic and inorganic contaminants may change the properties of soil. Recent studies have shown that the heavy metal contaminants affect the plasticity and consolidation behaviours. However, little is known about the effects of heavy metals on the behaviour of different types of clay, especially how clay behaves when multiple heavy metals are present in clay. The paper will present results from tests on the effect of three different heavy metal ions used separately, and mixed together in combinations, on the liquid limit $\left(\mathrm{w}_{\mathrm{L}}\right)$, plastic limit ( $\left.\mathrm{WP}_{\mathrm{P}}\right)$ and plasticity index (PI) of kaolin, bentonite, mixtures of kaolin and bentonite and reconstituted Lucera clay. It is found that plasticity index of bentonite is reduced significantly with the addition of heavy metals while PI increases slightly in kaolin. A 1:1 clay mixture of kaolin and bentonite showed significant reduction, while reconstituted Lucera clay has shown small reduction with the addition of heavy metals. It is found that at higher concentrations of copper and zinc cations, the effect takes reverse trend on the liquid limit of kaolin and similar behaviour was observed on the bentonite at higher concentrations of lead ion. Interestingly, lead ion exhibited a significant effect on the plasticity of bentonite when tested with $\mathrm{NaCl}$ solution as pore fluid.
\end{abstract}

\section{Introduction}

The behaviour of soil is complex in natural environment. The pore fluid chemistry is a significant factor in how soil behaves. The presence of salts, especially alkali metal salts in the soil and the pore fluid have been widely investigated [1-7].

Physical and mechanical properties of soils, particularly clay, are affected by the pore fluid composition and it can vary due to natural and anthropogenic processes [8]. Soil in general has a high capacity to retain metals and also has low solubility of metals, depending on the minerology of the soil, concentration of metal ions, cation exchange capacity of the soil and organic matter content [9]. Di Maio, et al. [6] investigated the effect of pore fluid and clay minerology on the volume change behaviour of a variety of clays and found that the smectite fraction is the most significant factor, an increase of the concentration of $\mathrm{NaCl}$ solution as pore fluid causing the compressibility of the clay to decrease. The effect of $\mathrm{NaCl}$ solution increases with the smectite content of the clay, due to the high water absorption capacity of smectite compared to kaolinite, illite and other clay minerals. However, Anson and Hawkins [10] reported the concentration of pore fluid having opposite effect of kaolinite and illite compared to smectite. The clay fraction of the soil therefore plays a significant role to retain metals and metal solubility, and with the clay fraction, the capacity to adsorb and retain metal ions increases [11].

While the smectite content of clay plays the most significant role in the compressibility of clays, the $\mathrm{pH}$ of the soil influences metal retention and solubility.
According to Basta, et al. [12], at higher $\mathrm{pH}$, clayey soils show a higher capacity to retain metal ions and have lower solubility of metals. The solubility of lead, cadmium, zinc and copper in soils, for example, increases with decrease in $\mathrm{pH}$, and metals naturally available in soils are less soluble than the metals added to the soil [13]. Metals in acidic soils are easily dissolved in pore fluid and become available, whereas calcareous soils have a low solubility of metals.

Metal ions are adsorbed by clayey soils to the negatively charged surface and hold on to it by forming a thin film. Adsorption occurs in two mechanisms; specific adsorption and non-specific adsorption [14]. Specific adsorption is depended on the $\mathrm{pH}$ as it involves stronger bonding between metal cations and negatively charged soil surface [15]. It is because at higher $\mathrm{pH}$, the pore fluid has less $\mathrm{H}^{+}$ions which can interact with the negatively charged soil surface and decrease its negative charge, causing stronger attraction and bonding between metal cations and negatively charged soil surfaces. Non-specific adsorption involves weak bonding and can easily be replaced by another metal cation with a stronger affinity to the soil surface. This phenomenon is called metal cation exchange.

Cation exchange is replacement of cations bonded to soil surface by another ion or ions that comes in contact with the soil. It is an electrostatic bonding controlled by diffusion and it is a reversible process [16]. Cation exchange capacity (CEC) is the capacity of a soil to hold onto cations and is an important property of the soil to retain essential nutrients and act as buffer against acidification of soils. Theriault and Nkongolo [17] investigated the effect of metal contamination on CEC in

\footnotetext{
" Corresponding author: abdulla.muththalib.16@ucl.ac.uk
} 
a mining region and reported that the metal contamination decreases the CEC compared to uncontaminated soils.

While some cation interaction with soil is reversible when subjected to leaching, for many cations including alkali metal cations and heavy metal cations, it is irreversible. Di Maio [18] investigated this phenomenon and reported that sodium chloride exposure to bentonite was reversible when re-exposed to water, but the potassium chloride and calcium chloride showed little change after long exposer to water. CEC of smectite is considerably higher than that of illite and kaolinite. Smectite has $80-150 \mathrm{meq} / 100 \mathrm{~g}$ while illite has 10-40 meq/100 and kaolinite has 3-15 meq/100g [19].

In natural environment, charged clay particles are surrounded by inhomogeneous ion layer known as electric double layer, which includes surface charge, the stern layer, and the diffuse layer [20].

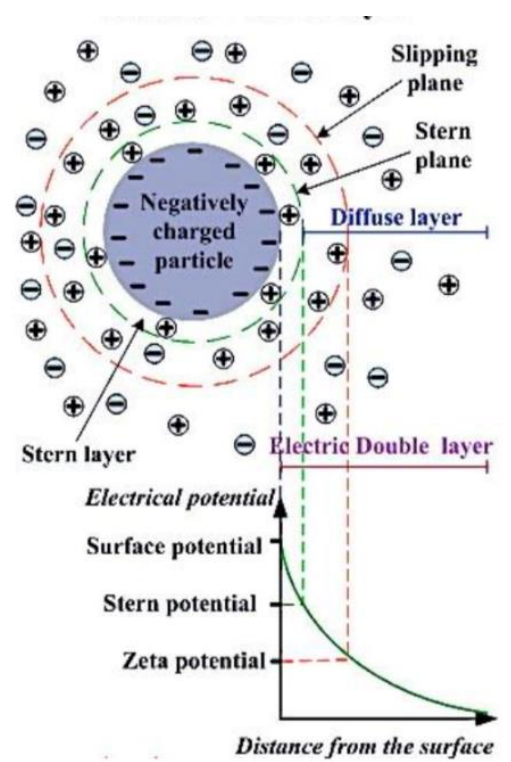

Fig. 1: Colloidal particle electrical double layer [20]

Pouralhosseni [20] also argued that double layer repulsion causes charged colloids to repel each other. Adding counter ions (opposite charge as clay surface) to the pore fluid can cause weaker repulsion between the particles.

The most important factor affecting compressibility of clay is when the double layer is compressed. Clay surfaces are generally negatively charged and when cations such as $\mathrm{Na}^{+}$and $\mathrm{K}^{+}$are added to a clay, compression of the double layer occurs, reducing the compressibility of the clay. According to Ravina and Maoramarco [21], the double layer compresses until there is no energy barrier when enough cations are added to the clay. When the double layer repulsion disappears, the van der Waals attraction dominates and particles form aggregates. Adsorption of cations on clay surface is the reason why repulsion caused by double layer around clay particles reduces.

Many of the researches on the effects of pore fluid composition on clay behaviour involve alkali metals such as $\mathrm{NaCl}, \mathrm{KCl}, \mathrm{CaCl}_{2}$ and organic substances, but few studies investigated the effect of heavy metals. Also, most existing studies focused on the behaviour of bentonite as it is widely used as a clay barrier for environmental management of waste sites. Di Maio [18] showed that the addition of alkali metals such as sodium, potassium and calcium ions decreases the liquid limit and plasticity index of bentonite, while Ouhadi, et al. [22] showed that the addition of zinc and lead ions decreases the liquid limit and plasticity index of bentonite. It was also found that the compressibility of bentonite decreases with an increase in the concentration of zinc and lead ions [22]. Reduction of compressibility is also reported by Dutta and Mishra [23] who also found an increase of the coefficient of consolidation $\left(\mathrm{c}_{\mathrm{v}}\right)$ with the concentration of heavy metal ions. The interaction of metal ions with the soil particles depends on a number of factors, but $\mathrm{pH}$ is found to be the factor which affects most, while the presence of cations in pore fluid alters the $\mathrm{pH}$ of the pore fluid [24].

Dutta and Mishra [25] investigated the influence of zinc, lead and copper ions present in leachates on the behaviour of two different bentonites and reported a decrease of plasticity with increasing heavy metal concentration; in their study $100 \mathrm{ppm}$ and $1000 \mathrm{ppm}$ were used. The ion concentration and $\mathrm{pH}$ are therefore the two factors which most affect the properties of bentonite.

Even though previous researches by Di Maio and Fenelli [4] among others found that kaolinite is little affected by cations in the pore fluid, Liu, et al. [26] found that heavy metal contamination decreases the unconfined compressive strength, electrical resistivity, and compression indices of kaolinite in the short term. However, the UCS and expansion strain of kaolinite may increase in the long term.

This paper presents results on the effect of heavy metals, namely copper, zinc, lead and combinations of these metal ions on the plasticity behaviour of bentonite, kaolin and mixtures of kaolin and bentonite, along with the effect of metals on a reconstituted natural clay from South Italy, Lucera clay. Since contamination of marine environment with the heavy metal is increasingly becoming a problem, the behaviour of the soil contaminated with heavy metal ions will also be presented when mixed with $\mathrm{NaCl}$ salt solution.

\section{Material and methods}

A commercial kaolin with kaolinite content of $75 \%$ and a commercial sodium bentonite with smectite content of 95\% provided by Fisher Scientific (UK), and reconstituted Lucera clay from Italy were used for the experiments. The Lucera clay is a natural stiff clay, a part of Sub-Apennine blue clay formation and it comes from the hilly slopes of the town of Lucera, in northern Apulia. The clay contains $77 \%$ illite-smectite mixed layers, $8 \%$ illite, $9 \%$ kaolinite and $6 \%$ chlorite [27]. The Lucera clay were reconstituted by cutting into pieces and softening in water and then mixing well to completely disaggregate. The clay was then air dried before being used for tests. A clay mixture of kaolin and bentonite with a ratio of $1: 1$ was also investigated. Each clay was tested with deionised water, $35 \mathrm{ppt} \mathrm{NaCl}$ solution and with heavy metals. Copper (II) nitrate, trihydrate $\left(\mathrm{Cu}\left(\mathrm{NO}_{3}\right)_{2} .3 \mathrm{H}_{2} \mathrm{O}\right)$ was used as source chemical for copper cations, lead (II) 
nitrate $\left(\mathrm{Pb}\left(\mathrm{NO}_{3}\right)_{2}\right)$ for lead cations and zinc (II) nitrate, hexahydrate $\left(\mathrm{Zn}\left(\mathrm{NO}_{3}\right)_{2} \cdot 6 \mathrm{H}_{2} \mathrm{O}\right)$ for zinc cations.

The molecular masses of each chemical were used to calculate the mass of each compound required to achieve the desired testing concentration. Instead of using pore fluid concentration, the concentration used was of weight of cations per kilogram of dry soil. The problem with prepreparing the pore fluid with a specific pore fluid concentration, which was done in most of the previous researches mentioned above, is that the cations available for soil for adsorption and cation exchange will differ depending on the amount of pore fluid added to clay. Therefore, keeping the heavy metal concentration with respect to the dry weight of the soil is considered to be more accurate. The concentrations of heavy metals 1000 ppm, $2000 \mathrm{ppm}$ and $5000 \mathrm{ppm}$, were tested. As well as testing separate heavy metal cation with each clay, heavy metals were also mixed to make combinations to test their combined effect.

The liquid limit $\left(\mathrm{w}_{\mathrm{L}}\right)$ and plastic limit $\left(\mathrm{w}_{\mathrm{P}}\right)$ tests were carried out according to the British Standard BS EN ISO 17892-12:2017. To ensure repeatability, wP test was repeated 3 times for each sample and 5-6 readings between cone penetration of $10 \mathrm{~mm}$ to $30 \mathrm{~mm}$ were taken for $\mathrm{w}_{\mathrm{L}}$ tests. For example, the standard deviation of 3 plastic limit tests done on each sample of kaolin was very small, between 0.1 and 0.3 , and the standard deviation of all kaolin samples with different heavy metals is 1.1 . The $\mathrm{R}^{2}$ value for all $\mathrm{w}_{\mathrm{L}}$ test graphs is between 0.98 and 1 . Sherwood [29] investigated the reproducibility of results of soil classification and found a standard deviation between 0.2-0.4 when the same person repeats wp test.

\section{Results}

The plasticity index of a clay (computed as $\mathrm{w}_{\mathrm{L}}-\mathrm{w}_{\mathrm{P}}$ ) helps to characterise its state based on its water content. Fig. 2 shows the effect of contamination by copper, zinc, lead and combinations of two or three heavy metals on the plasticity index of pure bentonite, pure kaolin and 1:1 clay mixture of kaolin and bentonite. The data are compared with results from tests using de-ionised water as pore fluid. It was found that the heavy metals had insignificant effects on the plastic limit of the soils tested so the trends seen in PI reflect mainly the changes in liquid limit. The results show that for all heavy metals tested, the effect of contamination is to decrease the plasticity index of bentonite. When using $35 \mathrm{ppt} \mathrm{NaCl}$ solution without heavy metal, the plasticity index of bentonite reduces by $113 \%$, while $1000 \mathrm{ppm}$ copper ion, $1000 \mathrm{ppm}$ lead ion and $1000 \mathrm{ppm}$ zinc ion reduce the plasticity index of bentonite by $6.4 \%, 17.3 \%$ and $11.8 \%$ respectively. In contrast, pure kaolin shows a small increase of its plasticity index when contaminated with heavy metal ions. Increases of 5.5\%, $6.8 \%$ and $2.9 \%$ were observed for copper, lead and zinc ion contamination respectively, while using an $\mathrm{NaCl}$ solution led to a reduced plasticity index of kaolin by $2.3 \%$. The data on the reconstituted natural Lucera clay suggest less sensitivity, with a reduction of plasticity when contaminated with all three heavy metal ions of $0.4 \%$ by copper ion, $0.6 \%$ by lead ion and $0.1 \%$ by zinc ion. Similarly, the addition of $\mathrm{NaCl}$ solution as pore fluid also only slightly reduced (1.0\%) the plasticity of Lucera clay. Lead ion affected the plasticity behaviour of all three clays most as a singular contaminant.

All three heavy metal ions were mixed with each other and tested with the clays to find out the effects of binary (two) and ternary (three) ion contamination on the plasticity of clays. The results show that clays contaminated with binary ion contamination have their plasticity more affected than with singular ion contamination. Among binary ion contaminations, copper and zinc ions cause the larger change, with a reduction by $34.1 \%$ in bentonite. The $40.7 \%$ reduction of plasticity index observed on the plasticity index of bentonite when contaminated with all three heavy metal ions is an even larger change than the change caused by any of the singular or binary ion contaminations.

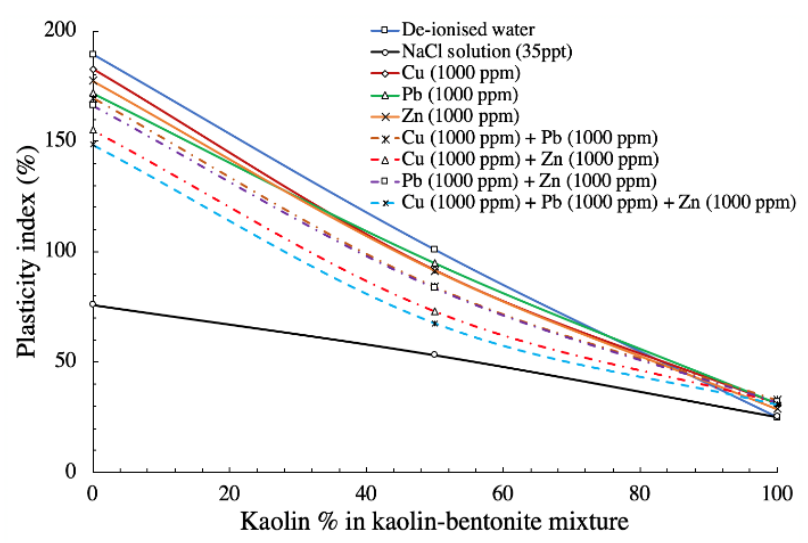

Fig. 2: Plasticity indices of kaolin-bentonite clay mixtures

Since the binary ion contamination has twice the concentration of single ion contamination, the effect of a single ion contamination with doubled concentration was also tested. It was found that it is not only the concentration which is affecting the plasticity behaviour, but there seems to be a combined effect of concentration and type and kinds of ions in the clay (Fig. 3). For example, when bentonite is contaminated with double the concentration of lead ion, the reduction observed on the $\mathrm{w}_{\mathrm{L}}$ is $10.4 \%$, while binary contamination of copper and zinc ions showed a reduction of $16.2 \%$.

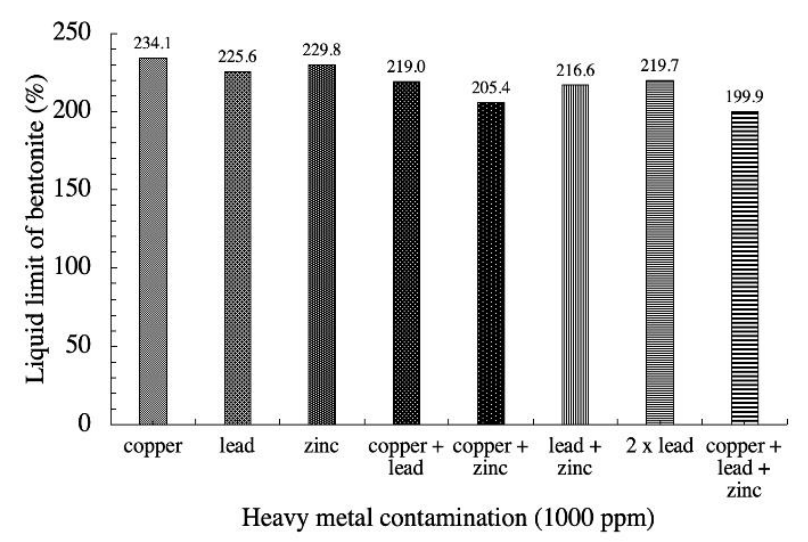

Fig. 3: Liquid limits of bentonite contaminated with heavy metals 
Fig. 4 shows the effect of heavy metal contamination on the plasticity index of kaolin, bentonite and Lucera clay. While the plasticity of bentonite is affected by heavy metal contamination significantly, the effect on kaolin and Lucera are very small.

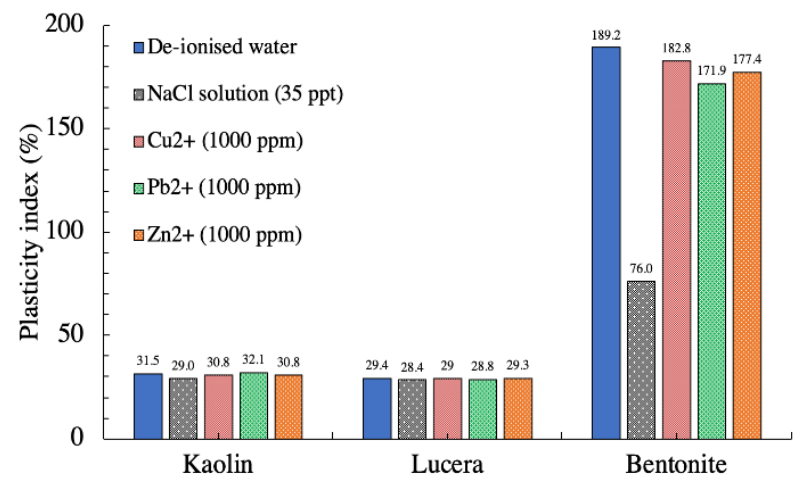

Fig. 4: Plasticity indices of kaolin, bentonite and Lucera clay

Fig. 5, Fig. 6 and Fig. 7 show the effect of concentration of heavy metal contamination on the plasticity of kaolin, bentonite and Lucera clay respectively. In kaolin, a $1000 \mathrm{ppm}$ concentration leads to an increase in $\mathrm{w}_{\mathrm{L}}$, but while further increases in the concentration of copper ion and zinc ion to $2000 \mathrm{ppm}$ and $5000 \mathrm{ppm}$ seem to reduce the liquid limit affect compared to $1000 \mathrm{ppm}$ concentration, the $\mathrm{w}_{\mathrm{L}}$ of kaolin contaminated with lead ion continues increasing with increasing concentration.

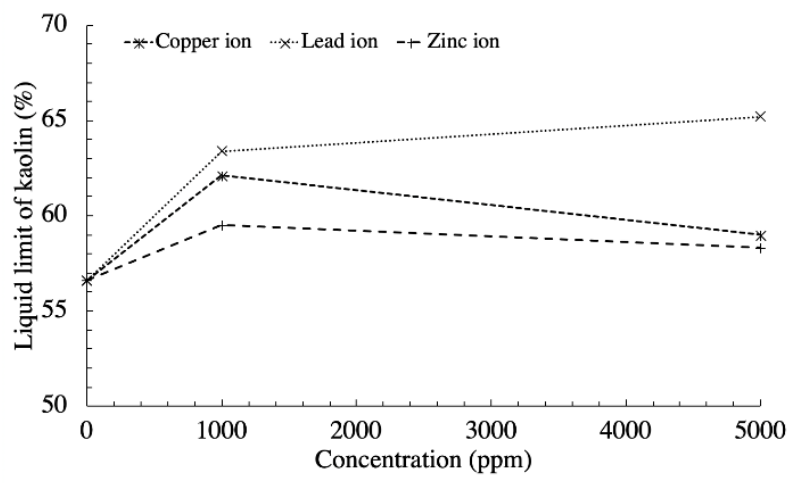

Fig. 5: Effect of heavy metal ion concentration on the $w_{L}$ of kaolin

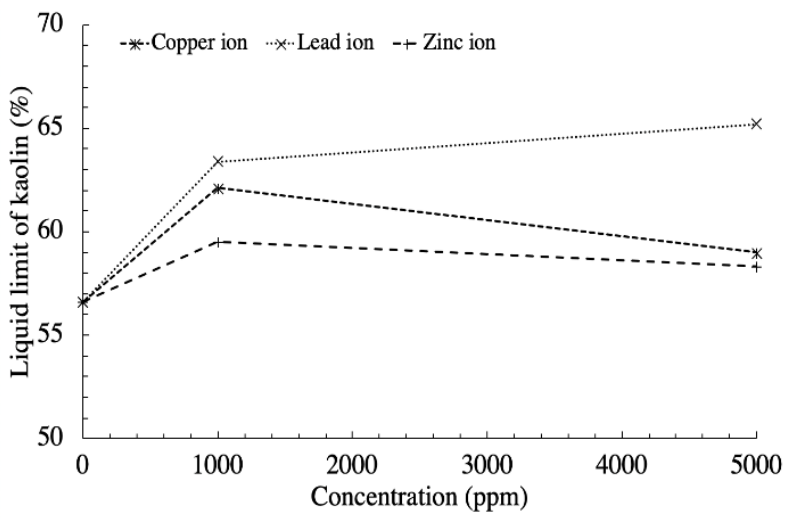

Fig. 6: Effect of lead ion concentration on the $\mathrm{w}_{\mathrm{L}}$ of bentonite
To investigate the effect of concentration in bentonite clay, the clay was tested with different concentrations of lead ion and results show the $\mathrm{w}_{\mathrm{L}}$ decreases with the concentration up to $2000 \mathrm{ppm}$ concentration and the $\mathrm{w}_{\mathrm{L}}$ increases slightly compared to $\mathrm{w}_{\mathrm{L}}$ of bentonite at 2000 ppm concentration of lead ion.

The $\mathrm{w}_{\mathrm{L}}$ of reconstituted Lucera clay, in contrast, decreases with increasing concentration, even though the effect is small compared to the effect on bentonite.

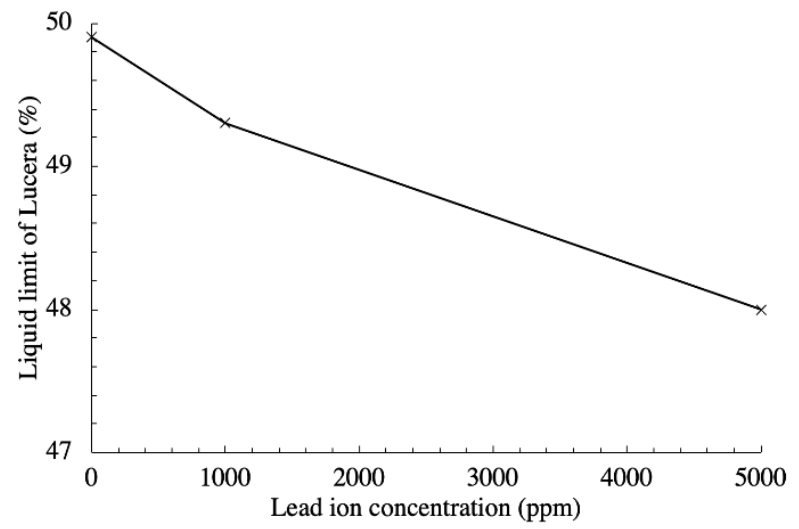

Fig. 7: Effect of lead ion concentration on the $\mathrm{w}_{\mathrm{L}}$ of Lucera

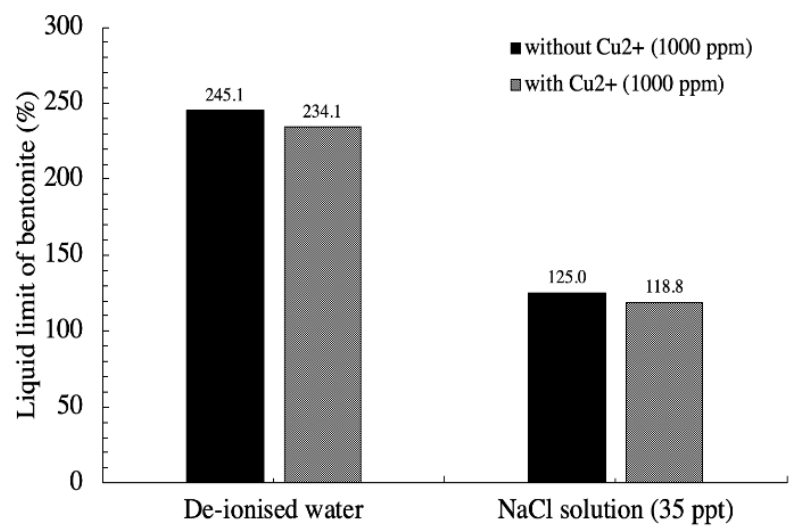

Fig. 8: Effect of copper ion on bentonite mixed with water and $\mathrm{NaCl}$ solution

Fig. 8 shows the effect of copper ion contamination on the $\mathrm{w}_{\mathrm{L}}$ of bentonite when $\mathrm{NaCl}$ solution is used as pore fluid compared to de-ionised water. Both with de-ionised water and $\mathrm{NaCl}$ solution, the $\mathrm{w}_{\mathrm{L}}$ decreases with the addition of copper ion to the clay. Even though $\mathrm{NaCl}$ solution decreases the liquid limit of bentonite almost by half, the reduction caused by copper ion is significant. The reduction of $\mathrm{w}_{\mathrm{L}}$ by copper ion in water is $11 \%$ and the reduction of $\mathrm{w}_{\mathrm{L}}$ caused by copper ion in $\mathrm{NaCl}$ solution is $6.2 \%$.

\section{Discussion}

The effect of adding single heavy metals to the clays tested here confirms what has been found in some previous studies $[18,23,25,26]$.

The clay minerals possess charge imbalances and these negative charges are balanced by hydrated cations forming a thin layer of water around it known as diffuse double layer (DDL). Contamination of clay with heavy 
metal ions results in the exchange of monovalent $\left(\mathrm{H}^{+}\right)$ cations with the divalent heavy metal cations $\left(\mathrm{Cu}^{2+}, \mathrm{Pb}^{2+}\right.$ and $\mathrm{Zn}^{2+}$ ). It is reported by Beetham, et al. [28] that the valence of the charge balancing cations primarily controls the thickness of the DDL. In bentonite, exchange of monovalent cations by divalent cations is reported to be the cause of reduction of DDL resulting lower plasticity indices. However this behaviour is prevalent in the clays containing significant level of smectite as Di Maio and Fenelli [4] reported that kaolinite is little affected by the cations in pore fluid due to its structural arrangement. Anson and Hawkins [10] reported kaolinite and illite having opposite effect to smectite by the cations in the pore fluid.

Even though the valence of cations plays a primary role determining the thickness of DDL, the type of cations also plays significant role. It was shown here that the effect of lead ion is significantly higher than that of copper and zinc ions on bentonite. It was also shown that when more than one heavy metal ions are present in the soil, there is a combined effect on the soil behaviour.

The effect of adding salt $(\mathrm{NaCl})$ is to decrease the plasticity index of kaolinite, bentonite and Lucera clay. The reduction in bentonite by $113 \%$ and much less by heavy metal contamination raises the question if heavy metal can have any effect of marine clays when marine clays are exposed to sea water. But the $6.1 \%$ reduction by copper ion observed on the $\mathrm{w}_{\mathrm{L}}$ of bentonite clearly shows heavy metal contamination can affect the behaviour of marine clay.

This study highlights the complexity of dealing with heavy metal contamination in soils. More tests to determine how the concentration and type of heavy metal affect the behaviour of clay when pore fluid is $\mathrm{NaCl}$ solution would be helpful in contributing to the knowledge.

The samples of kaolin-bentonite clay mixtures tested for this study may not represent in-situ conditions in terms of mineralogy, however, the results give an insight in how the plasticity of clay behaves in the presence of contaminants with different minerology.

\section{Conclusion}

The contamination of clay with heavy metal ions decreases plasticity of bentonite significantly, reduces plasticity of Lucera clay slightly, but increases plasticity of kaolin. Lead contamination affects all three clays more than any other heavy metal contamination tested. The effect of concentration of heavy metal contamination is not linear. The effect reduces with the increase of the concentration and with some heavy metal ions, the effect reverses at higher concentrations. Heavy metal contamination affects the plasticity of bentonite even when the pore fluid is $\mathrm{NaCl}$ solution showing the heavy metal contamination of marine clay also can have significant effect on the clay behaviour.

Heavy metals are hazardous substances to human, plant and other animals. However, the effect of heavy metal ions on clays, especially bentonite shows heavy metals interact with soils in a way that it can remain bonded to clay mineral surfaces unless high valence cations replace them or soil $\mathrm{pH}$ changes significantly for clay minerals to desorb the heavy metal cations. The implication of these findings indicates it is possible to rehabilitate and use contaminated lands without removing the heavy metal ions in soil and mitigate the dangers posed by the heavy metal contaminations.

Finally, there is still need for further investigations, especially compressibility behaviour, shearing strength, time effect and stabilisation with additives.

The authors would like to acknowledge the help from Politecnico Di Bari, Italy for providing Lucera clay sample for the investigation. Abdulla Muththalib thanks Islamic Development Bank (IDB) and University College London (UCL) for the award of joint PhD scholarship and Department of Civil, Environmental and Geomatic Engineering of UCL for all the support and assistance.

\section{References}

1. M. Calvello, M. Lasco, R. Vassallo, and C. Di Maio, Italian Geotechnical Journal, 1, p. 34-46 (2005)

2. C. Di Maio, Geotechnique, 48, 3, p. 433-436 (1998)

3. C. Di Maio, Geotechnique, 46, 4, p. 695-707 (1996)

4. C. Di Maio and G.B. Fenelli, Geotechnique, 44, 2, p. 217-226 (1994)

5. C. Di Maio and R. Onorati. in VIII International Symposium on landslides, Cardiff (2000)

6. C. Di Maio, L. Santoli, and P. Schiavone, Mechanics of Materials, 36, 5, p. 435-451( 2004)

7. D.M. Pontolillo, J. De Rosa, G. Scaringi, and C. Di Maio, in Vi Italian Conference of Researchers in Geotechnical Engineering, Cnrig2016 Geotechnical Engineering in Multidisciplinary Research: From Microscale to Regional Scale, p. 6974 (2016)

8. I.T. Rosenqvist, Philosophical Transactions of the Royal Society of London. Series A, Mathematical and Physical Sciences, 311, 1517, p. 369-373 (1984)

9. C.E. Martínez and H.L. Motto, Environ. Pollut., 107, 1, p. 153-158 (2000)

10. R.W.W. Anson and A.B. Hawkins, Geotechnique, 48, 6, p. 787-800 (1998)

11. N. Cavallaro and M.B. McBride, Soil Sci. Soc. Am. J., 48, 5, p. 1050-1054 (1984)

12. N.T. Basta, D.J. Pantone, and M.A. Tabatabai, AGRON. J.,. 85, 5, p. 1054-1057 (1993)

13. C.E. Martinez., Rutgers The State University of New Jersey - New Brunswick: Ann Arbor. p. 108 (1995)

14. M.B. McBride, Environmental Chemistry of Soils., New York: Oxford University Press (1994)

15. H.B. Bradl, J. of Colloid and Interface Science, 277, 1, p. 1-18 (2004)

16. B.E. Reed and S.R. Cline, Separation Science and Technology, 29, 12, p. 1529-1551 (1994)

17. G. Theriault and K. Nkongolo, Am. J. Environ. Sci., 12, 2, p. 55-62 (2016) 
18. C. Di Maio, The influence of pore fluid composition on the residual shear strength of some natural clayey soils. Landslides, ed. K. Senneset, Rotterdam: A a Balkema. 1189-1194 (1996)

19. M.J. Ridge, SPWLA-1983-vXXIVn3a1, 24, 3, p. 6 (1983)

20. S.S. Pouralhosseni, in Department of Chemical and Materials Engineering, University of Alberta (2014)

21. L. Ravina and N. Maoramarco, Zeta-Meter, Inc. (1993)

22. V.R. Ouhadi, R.N. Yong, and M. Sedighi, Applied Clay Science, 32, 3, p. 217-231 (2006)

23. J. Dutta and A.K. Mishra, Journal of Hazardous, Toxic, and Radioactive Waste, 21, 3 (2017)

24. R.N. Yong, Geoenvironmental engineering: Contaminated soils, pollutant fate, and mitigation. CRC press (2000)

25. J. Dutta and A.K. Mishra, Environmental Earth Sciences, 75, 11, p. 10 (2016)

26. Z. Liu, X. Ma, and W. Dai, Trans Tech Publications: Applied Mechanics and Materials. p. 1921-1929 (2011)

27. S. Guglielmi, in Department of Civil, Environmental, Land, Building Engineering and Chemistry, Politecnico di Bari, p. 578 (2017)

28. P. Beetham, T. Dijkstra, N. Dixon, P. Fleming, R. Hutchison, and J. Bateman, Proceedings of the Institution of Civil Engineers - Ground Improvement, 168, 2, p. 81-95 (2015)

29. P.T. Sherwood, PB 194 134. Crowthorne, Berk.: Road Research Laboratory, Earthworks and Foundations Section; [Reproduced by the Clearinghouse for Federal Scientific \& Technical Information, Springfield, Va.] (1970) 